\title{
Complications of Colonic Stenting: A Case of Stent Migration and Fracture
}

A 67-year-old woman underwent stent insertion (Wallstent $22 \mathrm{~mm}$ diameter, $6 \mathrm{~cm}$ long, Schneider, Bulach, Switzerland) for obstructing, metastatic, sigmoid colon cancer. Although abdominal decompression was achieved, the stent migrated to the rectum on the second day. After retrieval of the displaced stent using manual traction and gentle anal dilation without anaesthesia, another stent (Memotherm $30 \mathrm{~mm}$ diameter, $10 \mathrm{~mm}$ long, Bard, Karlsruhe, Germany) was inserted.

At 5 months later, the patient spontaneously passed part of the second stent and subsequently developed tenesmus and rectal bleeding. Flexible sigmoidoscopy and abdominal radiography showed stent fracture, with the distal portion hanging down into the rectum. (Figures $\mathbf{1 , 2}$ ). With the patient under general anaesthesia, the fractured segment of the stent was retrieved using biopsy forceps through a rigid sigmoidoscope. Further abdominal radiography showed that approximately $40 \%$ of the stent remained in situ across the tumour, achieving luminal patency. The patient has since remained well (followed-up for 3 months).

Colonic stent migration can occur in 3$22 \%$ of cases [ $1-3]$. Stenosis from extrinsic compression and laser pretreatment or chemotherapy may be factors precipitating stent migration $[3,4]$. The relatively small diameter of the Wallstent may also be contributory, especially in the distal colon.

In contrast, colonic stent fracture appears to be a rare complication having been reported in only three cases [5]. Constant compressive force within a fibrotic benign stricture and shearing forces from acute stent angulation have been proposed as the main reasons for fracture. Colonic peristalsis in conjunction with stool impaction may also play a part.

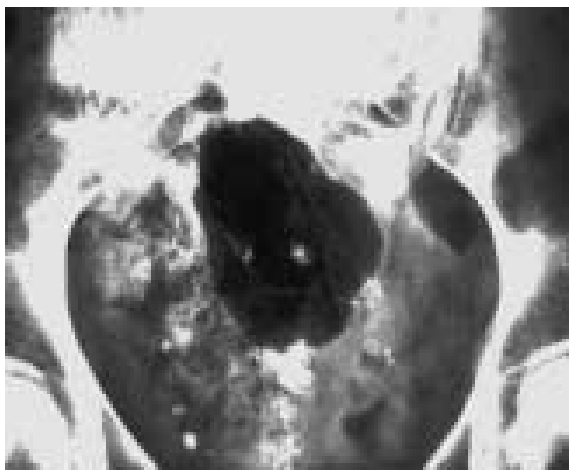

Figure 1 Abdominal radiography demonstrating stent fracture at the rectosigmoid junction (anteroposterior view).

Because of the steady increase in the use of colonic stents [1], clinicians should be aware of complications related to stent insertion. In the future, endoscopic removal of fractured stent pieces might be facilitated by use of wire cutters through the flexible sigmoidoscope in conjunction with an atraumatic overtube, avoiding general anaesthesia.

\section{N. Suzuki' ${ }^{1}$ B. P. Saunders ${ }^{1}$,}

S. Thomas-Gibson', M. Marshall²,

S. Halligan², J. M. A. Northover ${ }^{3}$

${ }^{1}$ Wolfson Unit for Endoscopy, St Mark's

Hospital, Harrow, Middlesex, UK

2 Department of Intestinal Imaging, St Mark's Hospital, , Harrow, Middlesex, UK

${ }^{3}$ Department of Surgery, St Mark's Hospital, Harrow, Middlesex, UK.

\section{References}

${ }^{1}$ Khot A, Wenk Lang A, Murali K et al. Systematic review of the efficacy and safety of colorectal stents. Br J Surg 2002; 89: 1096 - 1102

2 Baron TH, Dean PA, Yates MR et al. Expandable metal stents for the treatment of colonic obstruction: techniques and outcomes. Gastrointest Endosc 1998; 47: $277-286$

${ }^{3}$ Wholey MH, Levine EA, Ferral $\mathrm{H}$ et al. Initial clinical experience with colonic stent placement. Am J Surg 1998; 175 : 194- 197

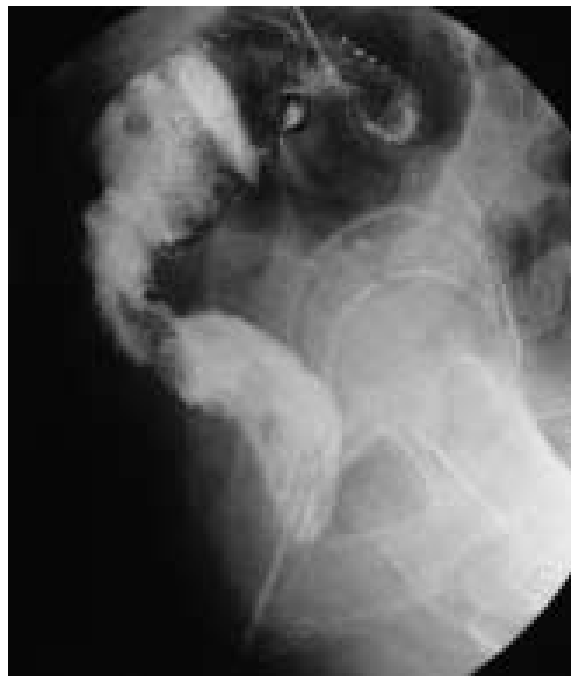

Figure 2 The distal part of the stent has fractured, but the proximal part remains in place across the tumour (lateral view).

${ }^{4}$ Rey JF, Romanczyk T, Greff M. Metal stents for palliation of rectal carcinoma: a preliminary report on 12 patients. Endoscopy 1995; 27: $501-504$

${ }^{5}$ Odurny A. Colonic anastomotic stenoses and Memotherm stent fracture: a report of three cases. Cardiovasc Intervent Radiol 2001; 24: 336-339

Corresponding Author

\section{B. P. Saunders, M.D.}

Wolfson Unit for Endoscopy

St Mark's Hospital

Watford Road

Harrow

Middlesex HA1 3UJ

UK

Fax: +44-20-84233588

E-mail: b.saunders@ic.ac.uk 